\title{
Uptake of Amino Acids by Three Species of Nereis (Annelida: Polychaeta). II. Effects of Anaerobiosis
}

\author{
N. O. G. Jørgensen and E. Kristensen \\ Institute of Ecology and Genetics, University of Aarhus, Ny Munkegade, DK-8000 Aarhus C, Denmark
}

\begin{abstract}
Uptake of 3 amino acids and release of individual amino acids and ammonia were investigated in the polychaetes Nereis succinea, $N$. diversicolor, and $N$. virens during $48 \mathrm{~h}$ of anoxic incubation. Uptake rates of alanine, serine, and glutamic acid from $5 \mu \mathrm{M}$ solutions were reduced to $30-85 \%$ of aerobic rates by $12 \mathrm{~h}$, but then stabilized for the remainder of the incubation period. Net release of amino acids from $N$. succinea and $N$. virens was insignificant during the first 4 h of anoxia; however, after $12 \mathrm{~h}$, amino acid release had increased in both species. During additional anoxic incubation, a decrease in net release rates was found. The opposite pattern occurred in $N$. diversicolor. Release rates of ammonia in all 3 species generally demonstrated tendencies similar to amino acid release rates. This similarity in release rates over time suggests that released amino acids are also metabolic waste products. The composition of the released amino acids varied greatly during incubation and no predominant amino acids were found. The concentration of free intracellular amino acids increased in all 3 species during anaerobiosis; alanine, glycine, and taurine were most abundant. Alanine typically increased during incubation, whereas the concentrations of glycine and taurine showed wide fluctuations.
\end{abstract}

\section{INTRODUCTION}

The benthic infauna is exposed to considerable changes in oxygen tension. In sheltered bays and shallow lagoons the sediment frequently becomes totally anoxic in summer (Ingvorsen and Jørgensen, 1979); this is especially pronounced during dark periods with no photosynthetic oxygen production. Oxygen depletion is not restricted to the sediment: the bottom water may also become anoxic, even in larger water bodies (Jørgensen, 1980). Invertebrates inhabiting such environments must be adapted to tolerating periods of oxygen depletion. Theede et al. (1969) reported that most species of the shallow-water Macoma-community actually are able to withstand one to several days of anoxic conditions. Nereis spp. differ in tolerance to oxygen deficiency (Theede et al., 1973); $N$. diversicolor exhibited the highest resistance to oxygen depletion, followed by $N$. virens, $N$. succinea, and $N$. pelagica.

Anaerobiosis affects the metabolism of the animals since catabolic metabolites cannot be oxidized. In Nereis spp. low-molecular-weight organic compounds such as acetate, propionate, lactate, and succinate accumulate in the cells (Schöttler, 1979). The concentration of free, intracellular alanine also increases du- ring anaerobiosis, but generally amino acids appear to be of minor importance as anaerobic endproducts (Schöttler, 1979). Epidermal absorption of free amino acids is also influenced by the oxygen tension. Costopulos et al. (1979) found that glycine uptake decreased in 2 species of polychaetes when the oxygen content was depleted, whereas the release of primary amines was unchanged.

The effects of longer periods of anaerobiosis on uptake and release of amino acids in 3 species of Nereis are reported in the present paper. Uptake rates of alanine, serine, and glutamic acid and release of individual amino acids were investigated during $48 \mathrm{~h}$ of anaerobiosis in $N$. succinea Frey \& Leuckart, $N$. diversicolor (O. F. Müller), and $N$. virens (Sars). In addition, the concentration of free, intracellular amino acids was followed.

\section{MATERIALS AND METHODS}

Anoxic seawater was produced by filtering natural, aged seawater through $0.45-\mu \mathrm{m}$ pore size filters, adjusting to a salinity of $18 \%$, and deoxygenating by flushing with $\mathrm{N}_{2}$ for at least $30 \mathrm{~min}$. To reduce the 
exposure to aerial oxygen, a 1-.l flask with a narrow opening was used for deoxygenation. Five $\mathrm{ml}$ of this anoxic seawater were transferred to 15 -mi clean serum vials kept in a stream of $\mathrm{N}_{2}$. At the same time, a Nereis was placed in the vial which then was closed with a serum cap. In control experiments, a drop of methylene blue solution was added through the serum seal after $1 h_{i}$ usually, no oxygen was detected.

Uptake of alanine, serine, and glutamic acid was investigated after $4,12,24$ and 48 h of anaerobiosis in 5 worms for each amino acid. At each of these times, solutions of alanine, serine, or glutamic acid (containing ${ }^{14} \mathrm{C}$-amino acids as tracers) were added to the vials with a Hamilton glass syringe to give final concentrations of $5 \mu \mathrm{M}$.Initially, the vials were gently shaken to mix the amino acid solution into the seawater. After $15 \mathrm{~min}$, the vials were opened and $1.0-\mathrm{ml}$ samples of the medium were taken for radioassay of amino acids. Uptake rates at each time were standardized to those for 100-mg individuals (Jørgensen and Kristensen, 1980). Initial aerobic uptake rates were taken from Jørgensen and Kristensen, (1980), and based on 20 worms for each amino acid.

Release of amino acids was investigated in clean glass vials containing $5 \mathrm{ml}$ of the anoxic seawater without addition of amino acids. After incubation periods of $0,4,12,24$, and $48 \mathrm{~h}, 0.2-\mathrm{ml}$ samples of the medium were withdrawn from 5 vials, each containing one Nereis individual, for analysis of amino acids. Extraction of free, intracellular amina acids in the worms was carried out with individuals from the release experiments after each incubation period. The worms were extracted in $80 \%$ ethanol for $24 \mathrm{~h}$, after which the concentration of individual amino acids was determined. All worm weights are given as wet weights. For details of analytical procedures and methods consult Jørgensen and Kristensen (1980)

\section{RESULTS}

\section{Anaerobic Uptake of Alanine, Serine and Glutamic Acid}

Uptake rates of alanine, serine, and glutamic acid decreased in all 3 species of Nereis during anaerobiosis over the first $12 \mathrm{~h}$ of incubation; thereafter uptake rates usually stabilized (Fig. 1). Maximum decreases occurred in alanine in $N$. succinea and $N$. diversicolor; in serine in $N$. virens. Thus, uptake rates were reduced by $60 \%$ (alanine) and $70 \%$ (serine). Glutamic acid uptake remained almost unchanged in $N$. diversicolor, whereas a decrease occurred in both $N$. succinea and $N$. virens.

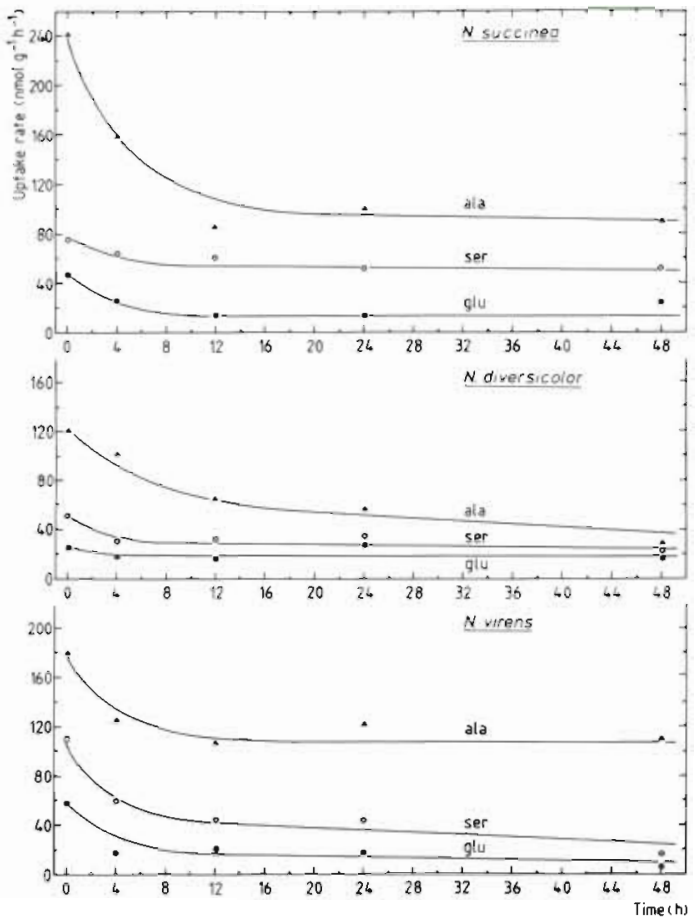

Fig. 1. Nereis succinea, $N$. diversicolor, and $N$. virens. Uptake rates of $5 \mu \mathrm{M}$ solutions of alanine, serine, and glutamic acid as a function of anaerobic exposure time. Average coefficient of correlation of the linear regressions: $0.65 \pm 0.29$. (Mean $\pm \mathrm{S}$. D., number of regressions $=36$ )

\section{Release of Amino Acids and Ammonia During Anaerobiosis}

The concentration of free amino acids in anoxic media with Nereis spp. increased from $1 \mu \mathrm{M}$ after $4 \mathrm{~h}$ of anaerobiosis to $3-8 \mu \mathrm{M}$ after $48 \mathrm{~h}$ (Fig. 2A). Higher mean concentrations of amino acids were found after 12 and 24 h in media with $N$. succinea and $N$. virens than with $N$. diversicolor; but after $48 \mathrm{~h}$, the highest concentrations occurred in $N$. diversicolor. Two of the 5 tested $N$. diversicolor were dead at this time; the higher amino acid concentration may indicate a severe anaerobic stress. However, interspecific variations in concentrations were not statistically significant as large individual differences occurred. An extremely pronounced release of amino acids was observed in a few instances. In preliminary experiments, amino acids (mainly phenylalanine and valine) released from $N$. virens increased the ambient concentrations to $29 \mu \mathrm{M}$ after $48 \mathrm{~h}$. This release was not caused by lysis from a dying worm; the worm concerned was still actively moving

Net release rates of amino acids differed only slightly in Nereis virens and $N$. succinea during anoxic incubation; but in $N$. diversicolor rates first decreased and then increased after $48 \mathrm{~h}$ (Fig. 2B). To eliminate 


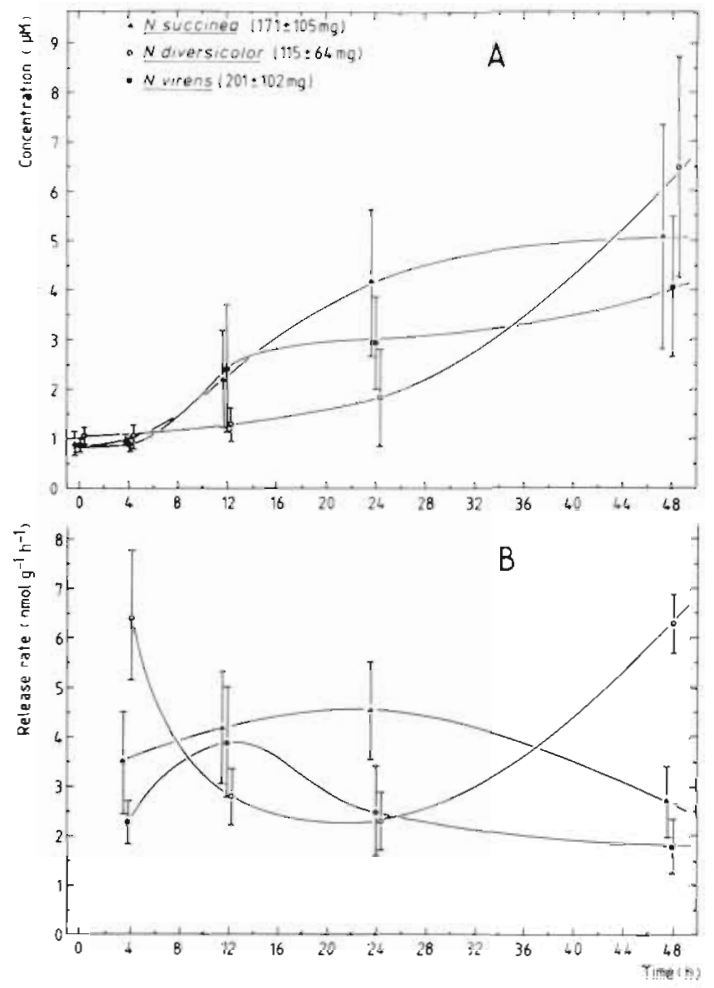

Fig. 2. Nereis succinea, $N$. diversicolor, and $N$. virens. Release of amino acids as a function of anaerobic exposure time. (A) Concentrations of amino acids in ambient media. Initial concentrations determined after $15 \mathrm{~min}$ of aerobic incubation. (B) Net release rates of amino acids, calculated from concentrations given in (A). Vertical bars: $\pm 1 \mathrm{~S}$. D. $(n=5)$. Weights of worms expressed as means $\pm \mathrm{S}$. D. Only 3 individuals of $N$. diversicolor were alive after $48 \mathrm{~h}$

possible divergent releases of amino acids due to handling of the animals, release rates were not calculated from the initial $15 \mathrm{~min}$ of incubation. However, Figure $2 \mathrm{~A}$ does not indicate such an initial release. The observed increase in net release rates in $N$. virens and $N$. succinea within the first $12 \mathrm{~h}$ need not indicate increased amino acid release. Since the decline of amino acid uptake (at least of alanine, serine and glutamic acid) stabilized after $12 \mathrm{~h}$, the increased net rates may have been caused by a reduced uptake of previously released amino acids. Net release rates varied considerably in $N$. diversicolor. From a rate of $6.5 \mathrm{nmol} \mathrm{g}^{-1} \mathrm{~h}^{-1}$ in the beginning, the rate decreased to $2.5 \mathrm{nmol} \mathrm{g}^{-1} \mathrm{~h}^{-1}$ after $24 \mathrm{~h}$; however, after $48 \mathrm{~h}$, the net release had increased to the initial rate.

Release of ammonia increased the initial concentration of $7 \mu \mathrm{M}$ to $160-200 \mu \mathrm{M}$ after $48 \mathrm{~h}$ (Fig. 3A). Ammonia concentrations increased from the beginning of incubation; in contrast, amino acid increase started after $4 \mathrm{~h}$. With this exception, ammonia and amino acid curves were similar, with a large increase of ammonia in all 3 species after $48 \mathrm{~h}$.

Ammonia release rates increased in all 3 species

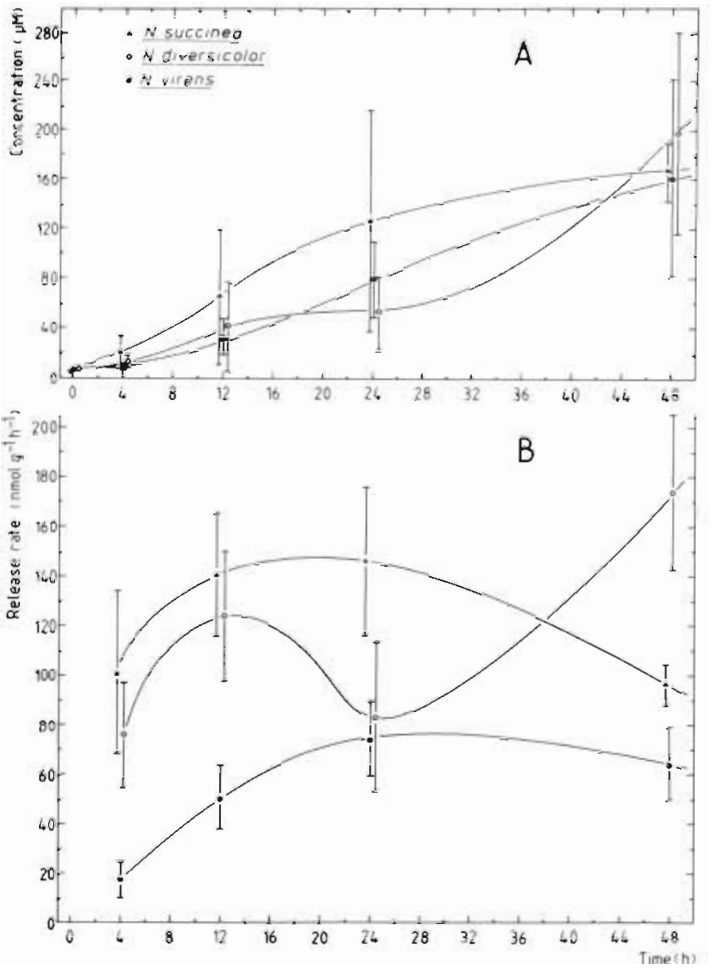

Fig. 3. Nereis succinea, $N$ diversicolor, and $N$. virens. Release of ammonia as a function of anaerobic exposure time. (A) Concentrations of ammonia in ambient media. Initial concentrations determined after $15 \mathrm{~min}$ of aerobic incubation. (B) Release rates of ammonia, calculated from concentrations given in (A). Otherwise as in legend to Figure 2

within the first $12 \mathrm{~h}$ of anoxia, thereafter rates decreased (Nereis succinea), stabilized ( $N$. virens), or increased ( $N$. diversicolor) (Fig. 3B). However, a small ammonia release occurred after $24 \mathrm{~h}$ in $N$. diversicolor. This coincides with a small net release of amino acids (Fig. 2B). Generally, the similarity in release rates of amino acids and ammonia in all 3 species suggests that released amino acids and ammonia have a similar origin.

The composition of individual, released amino acids changed considerably during anaerobic incubation and not direct relations between release of individual amino acids, incubation time, and species were observed (Fig. 4). This was typically during anaerobiosis in Nereis succinea in which the average ambient concentrations of serine, glycine and alanine generally decreased, while taurine increased. Other amino acids exhibited less consistent patterns. Leucine was insignificant at the beginning and after $48 \mathrm{~h}$, but after $12 \mathrm{~h}$, it amounted to $36 \%$ of the amino acids released. Glutamate and AABA were found only after $48 \mathrm{~h}$. Large variations in both individual and total concentrations of released amino acids also occurred in the 2 other species, as indicated by the error bars in Figure 2. Thus, after $48 \mathrm{~h}$, valine and arginine consti- 


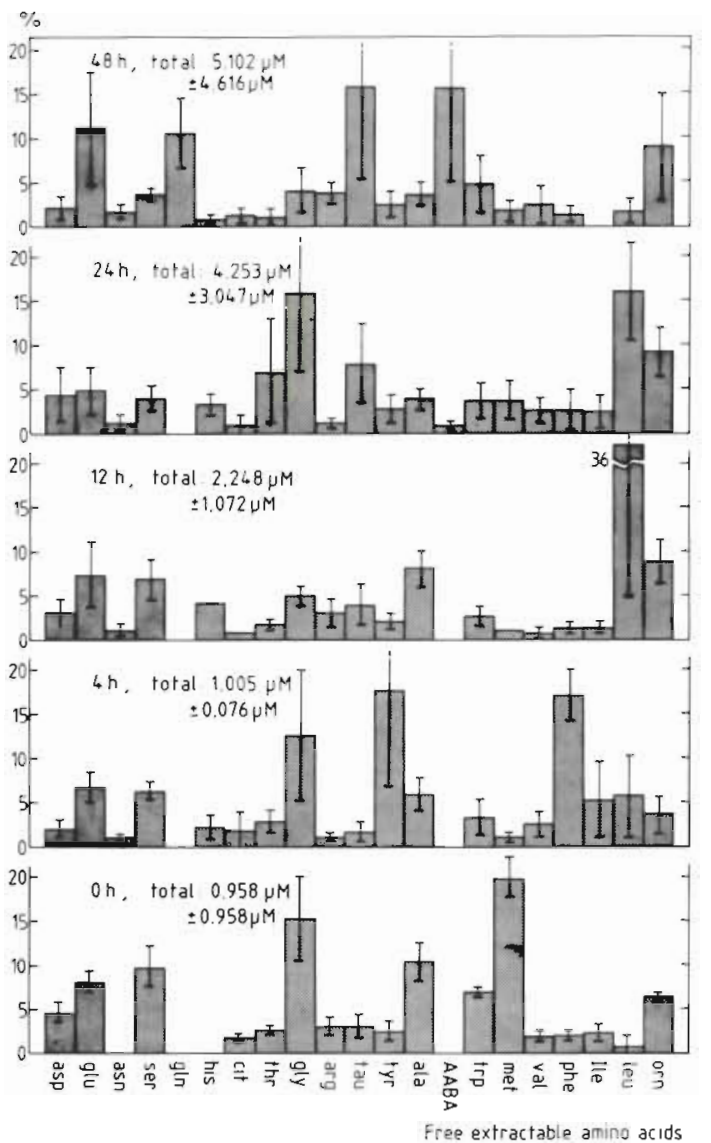

Fig. 4. Nereis succinea. Composition of amino acids released during anoxic incubation. Total amino acid concentrations (means $\pm S$. D.) and mean molar-percentages of 5 individuals. Vertical bars: $\pm 1 \mathrm{~S} . \mathrm{D}$. $(n=5)$. Amino acids presented in chromatographic elution order. (AABA $=a$-aminobutyric acid)

tuted $52 \%$ of the total amino acid content in media with $N$. virens, while glutamic acid, taurine, and serine constituted $49 \%$ in $N$. diversicolor. Ornithine which, according to Jørgensen and Kristensen (1980), accounts for a large fraction of the amino acids released under aerobic conditions, usually amounted to $5-10 \%$ of the total release during anaerobiosis.

\section{Free Extractable Amino Acids (FEAA) in the Nereids During Anaerobiosis}

Changes in the predominant free intracellular amino acids alanine, glycine, and taurine increased the total internal concentrations of amino acids in all 3 Nereis spp. (Fig. 5). In most cases a large increase occurred within the first $4 \mathrm{~h}$ of incubation. In $N$. succinea, the concentration of alanine reached a maximum after $12 \mathrm{~h}$, then slowly declined. Glycine concentrations varied greatly during incubation. After an initial increase for the first $4 \mathrm{~h}$, the concentration abruptly decreased until $12 \mathrm{~h}$. After $24 \mathrm{~h}$ glycine had increased again, but

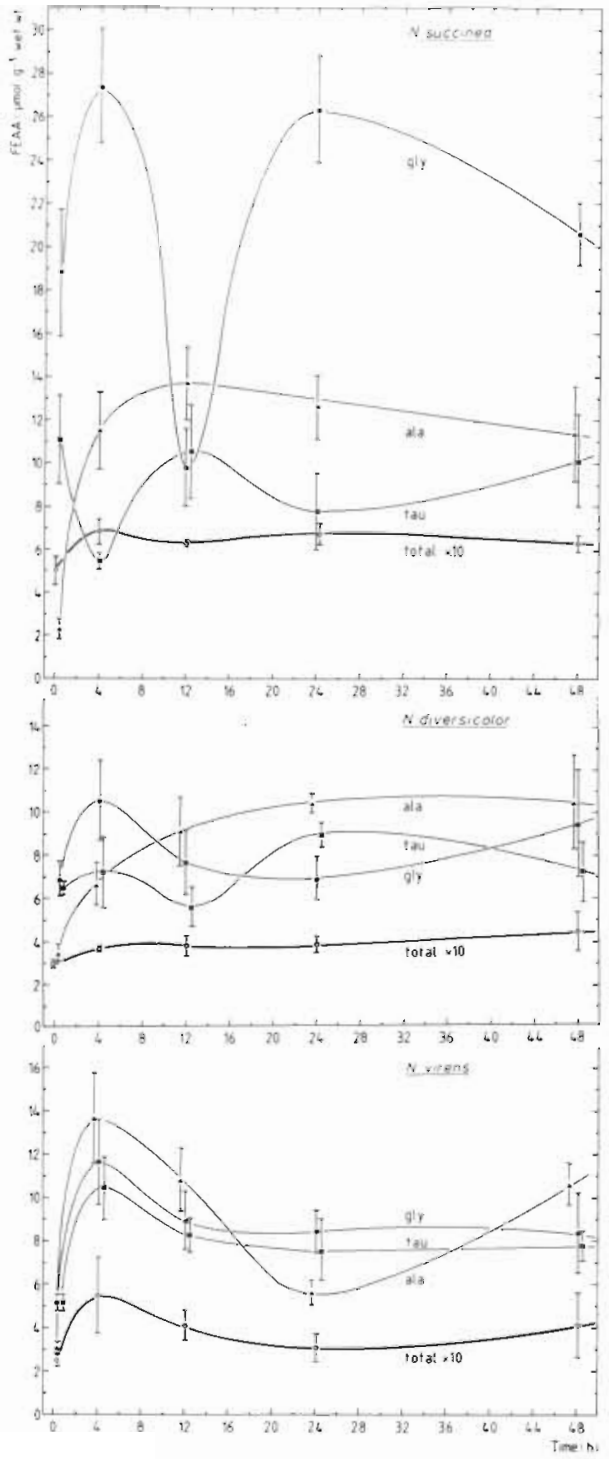

Fig. 5. Nereis succinea, $N$. diversicolor, and $N$. virens. Concentrations of free, extractable amino acids as a function of anaerobic exposure time. Total concentrations shown in 1:10 scale. Vertical bars: \pm 1 S. D. $(n=5)$

there was a slow decreased until $12 \mathrm{~h}$. After $24 \mathrm{~h}$ glycine had increased again, but there was a slow decrease until the end of incubation. The opposite course was found in taurine. In $N$. diversicolor, the concentration of alanine increased until stabilization occurred after $24 \mathrm{~h}$. The concentration of glycine and taurine increased in the beginning, but during the remaining incubation period, no consistent pattern was observed. In $N$. virens all 3 amino acids increased initially, but after $4 \mathrm{~h}$, the concentration of glycine and taurine decreased and stabilized at similar levels of about $8 \mu \mathrm{mol} \mathrm{g}{ }^{-1}$. Alanine also decreased after $4 \mathrm{~h}$, but after 24 h the concentration increased again.

The remaining FEAA exhibited statistically insig- 
nificant variations. Next to alanine, glycine, and taurine, glutamic acid was most common, accounting for $6-8 \%$ of the total amino acid concentrations.

The total concentrations of FEAA revealed the greatest changes in Nereis virens while the highest concentration occurred in $N$. succinea (Fig. 5). The average concentration of free amino acids in $N$. virens increased from the initial $26 \mu \mathrm{mol} \mathrm{g}{ }^{-1}$ to $55 \mu \mathrm{mol} \mathrm{g} \mathrm{g}^{-1}$ after $4 \mathrm{~h}$; thereafter the concentration declined to about $40 \mu \mathrm{mol} \mathrm{g}{ }^{-1}$. In $N$. diversicolor, the concentration increased from $29 \mu \mathrm{mol} \mathrm{g}^{-1}$ to a rather constant level of $40 \mu \mathrm{mol} \mathrm{g}^{-1}$ during the $48 \mathrm{~h}$ of anaerobiosis. In $N$. succinea the initial concentration of $51 \mu \mathrm{mol} \mathrm{g}^{-1}$ increased to $68 \mu \mathrm{mol} \mathrm{g}{ }^{-1}$ after $4 \mathrm{~h}$; this level was maintained during the remainder of the incubation period.

\section{Viability During Anaerobiosis}

All 3 Nereis species turned out to be highly resistant to anoxic conditions. Only two individuals of $N$. diversicolor died after $48 \mathrm{~h}$ of anaerobiosis. The worms generally reduced their activity during anoxic incubation, but creeping movements were regularly observed.

\section{DISCUSSION}

Epidermal amino acid uptake in marine invertebrates is accomplished by active, mediated transport driven by energy from hydrolysis of ATP (Lehninger, 1972; Bamford and McCrea, 1975). During anaerobic conditions in Nereis spp., a 30-40\% reduction in the concentration of free ATP was observed (Schöttler, 1979). The limited access to energy may thus be reflected in decreased rates of energy-requiring processes, e.g. absorption of free amino acids. In the present study, uptake rates of alanine, serine, and glutamic acid actually declined during anaerobiosis (Fig. 1). After initial reduction, uptake rates stabilized at $15-65 \%$ lower levels. This is in agreement with Costopulos et al. (1979) who report that anaerobic uptake of glycine in 2 polychaetes (Pareurythöe and Marphysa) was reduced to $32-46 \%$ of aerobic rates. Anaerobiosis appeared to cause varying degrees of physiological stress to the Nereis individuals tested: individual uptake rates were rather inconsistent, as indicated by low coefficients of correlation.

Amino acids were released from the Nereis spp. examined simultaneously with their uptake. This release was insignificant during the first $4 \mathrm{~h}$ of incubation, but after $12 \mathrm{~h}$, the concentration of free amino acids had increased in the media (Fig. 2). During this apparent lag period in release, uptake rates of alanine, serine, and glutamic acid were higher than after 24 and $48 \mathrm{~h}$ (Fig. 1). Simultaneous uptake of released amino acids may thus explain the low concentrations at the beginning of anoxic incubation. Correspondingly, increases of net release rates of amino acids within the initial $12 \mathrm{~h}$ in $N$. virens and $N$. succinea may have been caused by a higher initial uptake of previously released amino acids. Alternatively, only small amounts of amino acids might have been released due to the short period of anoxic exposure. Only minor release of primary amines was observed in Pareurythöe and Marphysa by Costopulos et al. (1979).

Release rates of amino acids under anoxic conditions are quantitatively similar to those found during aerobic conditions (Jørgensen and Kristensen, 1980). Rates of aerobic net release of amino acids were not calculated in this paper, but under identical experimental conditions, concentrations of released amino acids similar to those reported here were found. Apparently, anaerobiosis does not increase the total amino acid release. However, the composition of amino acids released under aerobic and anaerobic incubations differs. Ornithine was predominantly released during aerobic conditions, and leucine, lysine, and taurine were also abundant. During anaerobiosis, the amino acid spectra showed great changes and no prevalent amino acids were found. According to Schöttler (1979), some anaerobic metabolites are released from Nereis spp. In $N$. succinea (Fig. 5) high concentrations of free intracellular glycine occurred after 4 and $24 \mathrm{~h}$. At the same time, glycine was an important released amino acid (Fig. 4); this indicates that intracellular amino acids may be lost from the worms. However, no relation between free intracellular concentrations and release rates were found for alanine and taurine.

Bacterial assimilation of released amino acids was not considered in the present experiments. During the $48 \mathrm{~h}$ incubations, bacteria initially occurring in the media $(0.45-\mu \mathrm{m}$ filtered) may have proliferated, and bacteria may have been added by faecal production of the worms. However, the composition of amino acids in the media (Fig. 4) is not indicative of high bacterial assimilation; amino acids slowly assimilated by both bacteria and worms, e. g. ornithine (Jørgensen and Kristensen, 1980), did not accumulate in the media.

Amino acids are part of the nitrogeneous wastes of several marine invertebrates (Pandian, 1975). The similarity in release rates of ammonia and amino acids (Figs 2 and 3) also suggests that amino acids, like ammonia, are metabolic 'waste' products. The increase of amino acids and ammonia release rates in the Nereis diversicolor experiments might be due to an enhanced metabolic rate under anaerobic stress: $40 \%$ of the individuals did not survive $48 \mathrm{~h}$ of anoxia. This increased mortality in $N$. diversicolor is not consistent with results by Theede et al. (1973) which demonstrated that this species possesses the highest resist- 
ance to anoxia of the nereids considered. However, differences in condition may have been responsible for the death of our $N$. diversicolor.

The larger pools of free amino acids in all 3 Nereis species during anoxia may have been partly due to accumulation of anaerobic endproducts. Thus, free alanine is typically derived from degradation of glycogen in annelids (Zebe, 1975), and glycogen is the main energy source in animals exposed to anaerobic conditions (Schmidt-Nielsen, 1975). When bivalves are exposed to anoxia, alanine increase is restricted to the initial incubation period (de Zwaan, 1977). This has also been observed in $N$. diversicolor, but not in $N$. virens (Schöttler, 1979). In the present study, free alanine increased in $N$. diversicolor and partly in $N$. succinea until stabilization occurred after $24 \mathrm{~h}$. In $N$. virens, however, alanine decreased after $4 \mathrm{~h}$, but increased again after $48 \mathrm{~h}$. The proportion of glycine and taurine also changed during anaerobiosis. This was expecially pronounced with glycine in $N$. succinea. It remains uncertain whether glycine and taurine are anaerobic endproducts. Increase in intracellular amino acids and other organic compounds affects the osmotic balance of the cells and is counterbalanced by absorbing ambient water (Schöttler, 1979).

Although oxygen deficiency reduced uptake rates of alanine, serine, and glutamic acid in the 3 Nereis species tested, significant accumulation of amino acids still prevailed. Thus, the total net release rate of amino acids never exceeded the individual uptake rate of alanine, serine, and glutamic acid during anaerobiosis. Aerobic net rates of amino acid uptake from natural interstitial concentrations in marine sediments in the 3 nereids range from 700-1200 $\mathrm{nmol} \mathrm{g}^{-1} \mathrm{~h}^{-1}$ (Jørgensen and Kristensen, 1980). In our anoxic experiments, net release rates smaller than $5 \mathrm{nmol} \mathrm{g}{ }^{-1} \mathrm{~h}^{-1}$ were usually found (assuming minor bacterial assimilation). Consequently, a large net influx of amino acids from natural concentrations still prevails during anaerobiosis. Amino acid uptake is of importance to the Nereis species examined: the absorbed amino acids participate in both catabolic and anabolic pathways (Jørgensen, 1979).

The extent to which anoxic conditions prevail in natural worm burrows is unknown. In undisturbed marine sediments, only the upper few millimeters contain free oxygen (Sørensen et al., 1979). Under in situ conditions we observed ventilation in Nereis tubes, but the quantitative significance of this water transport in terms of oxygen supply is not known. According to Wells and Dales (1951) ventilation rates of $N$. diversicolor are reduced under oxygen depletion. The oxygen content of worm burrows is probably determined by several factors, for example, respiration rate, reducing power of the sediment, size and depth of the burrow, ventilation of the worms, and exchange dynamics with overlying bottom waters. We are presently studying these aspects.

Acknowledgements. We are grateful to Dr L. Cammen for reading and criticizing our manuscript. The study was supported by a grant trom The University of Aarhus (to N. O. G. Jorgensen) and from The Danish Natural Science Research Council, grant No. 511-15884 (chromatographic equipment).

\section{LITERATURE CITED}

Bamford, D. R., McCrea, R. (1975). Active absorption of neutral and basic amino acids by the gills of the common cockle, Cerastoderma edule. Comp. Biochem. Physiol. 50: $811-817$

Costopulos, J. M., Stephens, G. C., Wright, S. H. (1979). Uptake of amino acids by marine polychaetes under anoxic conditions. Biol. Bull. mar. biol. Lab., Woods Hole 157: $434-445$

Ingvorsen, K., Jørgensen, B. B. (1979). Combined measurements of oxygen and sulfide in water samples. Limnol. Oceanogr. 24: 390-393

Jørgensen, B. B. (1980). Seasonal oxygen depletion in the bottom waters of a Danish fjord and its effect on the benthic community. Oikos 34: 68-76

Jorgensen, N. O. G. (1979). Uptake of L-valine and other amino acids by the polychaete Nereis virens. Mar Biol. 52: 45-52

Jorgensen, N. O. G., Kristensen, E. (1980). Uptake of amino acids by three species of Nereis. (Annelida: Polychaeta). $\mathrm{l}$. Transport kinetics and net uptake from natural concentrations. Mar. Ecol. Prog. Ser. 3: 329-340

Lehninger, A. L. (1972). Biochemistry, Worth Publishers Inc., New York

Pandian, I. J. (1975). Mechanisms of Heterotrophy. In: Kinne, O. (ed) Marine ecology, Vol. II, Physiological mechanisms, Part 1. Wiley, London, pp. 61-249

Schmidt-Nielsen, K. (1975). Animal physiology, adaption and environment, Cambridge University Press, Cambridge

Schöttler, U. (1919). On the anaerobic metabolisms of three species of Nereis (Annelida). Mar. Ecol. Prog. Ser. 1: $249-254$

Sorensen, J. Jorgensen, B. B., Revsbech, N. P. (1979). A comparison of oxygen, nitrate, and sulphate respiration in coastal marine sediments. Microb. Ecol. 5: 105-115

Theede, H., Ponat, A., Hiroki, K., Schlieper, C. (1969). Studies on the resistance of marine invertebrates to oxygen-deficiency and hydrogen sulphide. Mar Biol. 2: 325-337

Theede, H., Schaudinn, J., Saffé, F. (1973). Ecophysiological. studies on four Nereis species of the Kiel Bay. Oikos 15 (Suppl.): 246-252

Wells, G. P., Dales, R. P. (1951). Spontaneous activity patterns in animal behaviour: The irrigation of the burrow in the polychaetes Chaetopterus variopedatus Renier and Nereis diversicolor O. F. Müller J. mar biol. Ass. U. K. 29 : $661-680$

Zebe, E. (1975). In vivo-Untersuchungen über den GlucoseAbbau bei Arenicola marina (Annelida, Polychaeta). J. comp. Physiol. 101: 135-145

Zwaan, A. de (1977). Anaerobic energy metabolism in bivalve molluscs. Oceanogr mar Biol. A. Rev. 15: 103-187

This paper was presented by Dr D. Siebers; it was accepted for printing on August 18, 1980 